\title{
Biotransformation of rice and sunflower side-streams by dikaryotic and monokaryotic strains of Pleurotus sapidus: Impact on phenolic profiles and bioactive properties
}

\author{
José Pinela $^{\mathrm{a}, 1}$, Alejandra B. Omarini ${ }^{\mathrm{b}, \mathrm{c}, 1}$, Dejan Stojković ${ }^{\mathrm{d}}$, Lillian Barros ${ }^{\mathrm{a}}$, Pablo D. Postemsky , $^{\mathrm{e}}$ \\ Ricardo C. Calhelha ${ }^{\mathrm{a}}$, Javier Breccia ${ }^{\mathrm{b}}$, Marcelo Fernández-Lahore ${ }^{\mathrm{c}}$, Marina Soković ${ }^{\mathrm{d}}$, \\ Isabel C.F.R. Ferreira ${ }^{\text {a,* }}$ \\ ${ }^{a}$ Centro de Investigação de Montanha (CIMO), Instituto Politécnico de Bragança, Campus de Santa Apolónia, 5300-253 Bragança, Portugal \\ ${ }^{\mathrm{b}}$ INCITAP Institute of Earth and Environmental Sciences of La Pampa (CONICET-UNLPam) National Scientific and Technical Research Council-National University of La \\ Pampa. Mendoza 109 (CP6300), Santa Rosa, La Pampa, Argentina \\ ${ }^{\mathrm{c}}$ Downstream Bioprocessing Laboratory, Jacobs University Bremen gGmbH. Campus Ring 1, CP28759 Bremen, Germany \\ 'University of Belgrade, Department of Plant Physiology, Institute for Biological Research "Siniša Stanković", Bulevar despota Stefana 142, Belgrade, Serbia \\ ${ }^{\mathrm{e}}$ Laboratorio de Biotecnología de Hongos Comestibles y Medicinales, CERZOS-UNS/CONICET, Camino de La Carrindaga Km7, Bahía Blanca 8000, Buenos Aires, \\ Argentina
}

\section{A R T I C L E I N F O}

\section{Keywords:}

Solid-state fermentation

Lignocellulosic substrates

Pleurotus sapidus

Phenolic compounds

Antioxidant activity

Antimicrobial activity

\begin{abstract}
A B S T R A C T
Fungi are known to modify the properties of lignocellulosic materials during solid-state fermentation (SSF). In this study, agricultural side-streams (sunflower seed hulls, rice husks and rice straw) were used as substrates for SSF with dikaryotic and monokaryotic strains of Pleurotus sapidus. The phenolic profiles of the mentioned substrates were characterized by LC-DAD/ESI-MS ${ }^{n}$ pre- and post- fermentation. Moreover, antioxidant, cytotoxic and antimicrobial activities were screened against oxidizable cellular substrates, tumour and primary cell lines, and different bacteria and fungi, respectively. The concentration of phenolic compounds in the crop side-streams was reduced after fermentation with both strains of the fungus. The fermented extracts also displayed lower antioxidant and cytotoxic activities and had no hepatotoxicity. The antimicrobial activity depended upon the crop side-stream and/or SSF conditions. These results indicate that $P$. sapidus represent a good candidate to modify the phenolic fraction presents in crop side-streams with a consequent decrease in its bioactivities. However, the SSF with $P$. sapidus strains play an interesting role in the detoxification of plant materials which can be used for different applications according to the "reduce - reuse - recycle" concept contributing with the sustainable land use and circular economy.
\end{abstract}

\section{Introduction}

Global cereal production has increased significantly in the last decades due to greater inputs of fertilizer, water, pesticides, new crop varieties, and other technologies. Following grain processing, 20-50\% of the biomass remains as side-streams, creating serious environmental problems due to microbial decomposition and leachate production. The biotransformation of crops side-streams using fungi could represent an important goal for a better use of the biomass following the principle of circular economy and to obtain a variety of high-value products, whereas reduces the waste disposal problem (Sadh, Kumar, Chawla, \& Duhan, 2018). The lignocellulosic material represents a valuable resource of bioactive compounds such as polysaccharides, hydrocarbons, polyphenols, organic acids, vitamins, fatty acids, proteins among others. Furthermore, it can be used as raw material to produce edible mushrooms, enzymes, nanocomposites or protein rich material (Bilal \& Iqbal, 2019; Omarini et al., 2019; Postemsky et al., 2019; Sadh et al., 2018; Torres-León et al., 2018). Additionally, antinutritional factors present in the plant material can be minimized through biotechnological processes for use as a food additive or in the formulation of balanced food for human or as animal fodder (Ghorai et al., 2009; Torres-León et al., 2018).

The white-rot fungal conversion of crop side-streams through solidstate fermentation (SSF) has got the potential to improve the

\footnotetext{
*Corresponding author.

E-mail address: iferreira@ipb.pt (I.C.F.R. Ferreira).

${ }^{1}$ The authors contributed equally.
} 
digestibility and nutrient availability of agricultural residues through a selective degradation of the plant materials and, on the other hand, as resource for production of new products and applications (Omarini et al., 2016; Sharma \& Arora, 2014; Shrivastava et al., 2011). During the SSF, fungi secrete a variety of extracellular enzymes able to disrupt plant cell wall (lignin), modify lignocellulosic structures and release of the desire compounds. Furthermore, these enzymes could also be used in different food processing industries as well as in the improvement of fodder quality (Bilal \& Iqbal, 2019; Ghorai et al., 2009). The treatment was demonstrated to be efficient for reducing lignin concentration and setup an optimization for low carbohydrate consumption per unit of lignin degradation (Shrivastava et al., 2011; Singhania, Sukumaran, Patel, Larroche, \& Pandey, 2010).

A high diversity of white-rot fungi has been applied to lignocellulosic substrates degradation; however, the use of edible mushrooms is attracting because they are food with high nutritional value and with a long history of safe use. Their products could thus be directly introduced in food, pharmaceutical, cosmetic or other applications (Ghorai et al., 2009). Amongst the different cultivated species, genus Pleurotus is a suitable choice considering that is the second most cultivated and consumed mushroom in the world (Espinosa-Páez et al., 2017). In particular, P. sapidus is easy to cultivate in solid and liquid fermentation, it has a short life cycle and it has demonstrated its potential for metabolite production and compound bioconversion. Additionally, it was determined that this fungus can generates monokaryotic strains which offer an interesting genotypic and phenotypic traits diversity and this fact opens new possibilities for their application as non-GMO biocatalysts in different processes (Omarini et al., 2019; Omarini, Plagemann, Schimanski, Krings, \& Berger, 2014; Postemsky et al., 2019).

The presence of bioactive compounds exerting positive effects on animals and human health and, at the same time, is a quality parameter for the nutritional values of a given food product. Phenolic compounds are considered as natural antioxidants and represent an important group of bioactive compounds of plant-based foods (Bessada, Barreira, Barros, Ferreira, \& Oliveira, 2016). On the other hand, bioactive phenolics in cereal grains are mainly located in the bran fraction and covalently bound to polysaccharides. They have low bioavailability because the complex bran matrix severely hinders their access to the necessary enzymes which contribute to their release in the mammalian gastrointestinal tract (Wang, He, \& Chen, 2014).

Regarding the targeted compounds that could be modified or release from plant-based materials, polyphenols deserve a considerable interest since they have been associated with a number of health-promoting effects, including the prevention of different types of cancer and coronary heart diseases (Perez-Vizcaino \& Fraga, 2018). In this way, these molecules, which are involved in defence systems of plants towards ultraviolet radiation and/or herbivory, have demonstrated antioxidant and anti-inflammatory activities, among other biological effects (Bessada et al., 2016; Dykes \& Rooney, 2007).

Considering the growing demand for bioactive compounds, the present work aims at the characterization of the phenolic fraction of rice and sunflower crops side-streams according to the "reduce - reuse recycle" concept. Different strains of the edible fungus $P$. sapidus (monokaryon (n) and dikaryon (2n)) were evaluated as biocatalyst for the SSF of the crop side-streams. The monokaryon strain was used as an innovative source of mycelia to valorize rice and sunflower side-stream biomass through SSF. The effect of the SSF with different $P$. sapidus strains on the phenolic fraction and the impact on their bioactivities was further explored.

\section{Material and methods}

\subsection{Chemicals and raw materials}

All standard compounds used for chromatographic (gallic acid, protocatechuic acid, chlorogenic acid, caffeic acid, $p$-hydroxybenzoic acid, ferulic acid, apigenin-6- $C$-glucoside; from Extrasynthèse, Genay, France) and bioactivity (trolox, dexamethasone, ellipticine, streptomycin, ampicillin, ketoconazole, bifonazole; from Sigma-Aldrich, St. Louis, MO, USA) analyse had a purity level of at least $95 \%$.

Sunflower seed hulls (Helianthus annuus) were obtained from Cargill S.A. Port Terminal (Bahía Blanca, Buenos Aires, Argentina), golden rice straw and husks (Oryza sativa) were obtained from Copra S.A. (Mercedes, Corrientes, Argentina).

\subsection{Microorganisms}

The dikaryotic strain Pleurotus sapidus Dk3174 (Institut für Lebensmittelchemie (LCI) fungi collection No. 343, Leibniz Universität Hannover, Germany) obtained by crossing two compatible monokaryons, Mk31 and Mk74 (Omarini et al., 2014) and the monokaryon P6 (Mk) derived from a germinated spore of the Dk (Dk3174) were employed (Postemsky et al., 2019). Strains were cultured in potato/ dextrose/agar medium (PDA, Carl Roth, Karlsruhe, Germany) for seven days at $25^{\circ} \mathrm{C}$ and stored at $4{ }^{\circ} \mathrm{C}$.

\subsection{Spawn preparation}

Spawn (inoculum) was prepared using $59.1 \%$ of boiled rice (Oryza sativa, 59.1\%) or wheat (Triticum durum, 59.1\%) grains supplemented with $0.1 \%(w / w)\left(\mathrm{CaCO}_{3}\right), 0.8 \% \mathrm{CaSO}_{4}$ and $40 \%$ water, by weight and placed in polypropylene bags (1.5-2.0 L). Bags were sterilized at $121{ }^{\circ} \mathrm{C}$ for $2 \mathrm{~h}$. Once cooled, each bag was inoculated with six pieces of mycelia from the Mk or the Dk grown on PDA plates. Incubation was performed for 15 days at $25^{\circ} \mathrm{C}$, in darkness, until mycelia had completely covered the grains (Omarini et al., 2016).

\subsection{Solid-state fermentation of rice and sunflower side-streams}

SSF of rice straw (RS), rice husks (RH) and sunflower seed hulls (SH) by the monokaryon P6 (MkP6) and the dikaryon Dk3174 (Dk) at pilotscale conditions was performed as previously described (Postemsky et al., 2019). Dried RS (10-14\% of humidity) was chopped until a particle size of $5-10 \mathrm{~cm}$, while RH and SH (9-12\% of humidity), were used directly. Substrates were prepared as follow: $39.1 \%$ lignocellulosic material (RS, $\mathrm{RH}$ or $\mathrm{SH})$, calcium salts $\left(0.8 \% \mathrm{CaSO}_{4}, 0.1 \% \mathrm{CaCO}_{3}\right)$ and water $(60 \%)$, by weight. Substrates were mixed and then sterilized at $121^{\circ} \mathrm{C}$ for $2 \mathrm{~h}$. After the material cooled, the substrates were inoculated with the Mk or Dk grain spawn $(8 \%, w / w)$. Spawn done with rice grain was used to inoculate RS and $\mathrm{RH}$, and the one done with wheat grain was used for SH. Inoculated substrate $(1 \mathrm{~kg})$ was packed in polyethylene bags ( $100 \mu \mathrm{m}$ thick, $40 \mathrm{~cm}$ long, $8 \mathrm{~cm}$ diameter, $2.0 \mathrm{~L}$ ) under aseptic conditions, sealed and then incubated until mycelium completely covered the substrate $\left(25{ }^{\circ} \mathrm{C}\right.$, in darkness, $16-20$ days). The substrate humidity and temperature were periodically checked during mycelium running to avoid moisture accumulation and thermogenesis inhibitory events which can impact on mycelium growth. During this period, the gas exchange was provided by making holes ( 4 holes of $1 \mathrm{~cm}^{2}$ ) alongside the plastic bag, following the standard cultivation protocols used for Pleurotus species. Only the set of experimental units inoculated with the dikaryon (Dk) strain were continued until fruiting bodies production. To induce mushroom morphogenesis (fructification), the inoculated bags were moved to an environmentally controlled area and the polypropylene bags were removed (Omarini et al., 2016). There, they were exposed to $25 \pm 3{ }^{\circ} \mathrm{C}$, with plenty of air renovation ( $>8$ air room volumes per day, $<400 \mathrm{ppm} \mathrm{CO}_{2}, 80-100 \%$ relative humidity and a $12 \mathrm{~h}$ photoperiod (100-500 lx irradiated from white fluorescent lights). Basidiomes (fructification) were cropped and the residual substrates called residual substrate or spent mushroom substrate (SMS) were preserved.

Samples (bags) inoculated with the Mk or Dk were collected at the 
full colonization phase (16-20 days), when all bag surfaces turned white (end of the incubation phase), and a set of samples inoculated with the Dk were collected after the fructification phase (55-65 days), according to the management used by mushroom cultivation industries. These two times were selected based on the standard periods used by mushroom cultivation farms (incubation and fructification) to explore new opportunities and to valorize the spent mushroom substrate. All samples were dried at $60 \pm 5{ }^{\circ} \mathrm{C}$ in a convection oven and milled to $1 \mathrm{~mm}$ particle size using a Thomas Model 4 Wiley ${ }^{\circledR}$ mill lab grinder to obtain the powdered samples, which were preserved at $-20{ }^{\circ} \mathrm{C}$ until analysis.

\subsection{Preparation of extracts}

Powdered samples $(\sim 1 \mathrm{~g})$ underwent to solid-liquid extraction twice with $30 \mathrm{~mL}$ 80:20 ethanol:water $(v / v)$ for $1 \mathrm{~h}$ at room temperature and filtered with paper Whatman $\mathrm{n}^{\circ} 4$, as previously described by Bessada et al. (2016). Ethanol was separated in a rotary evaporator (Büchi R-210, Flawil, Switzerland) and water was lyophilized (FreeZone 4.5, Labconco, Kansas City, USA).

\subsection{Analysis of phenolic compounds}

The extracts $(\sim 40 \mathrm{mg})$ were dissolved in $1 \mathrm{~mL}$ of 20:80 methanol:water $(v / v)$ and filtered through $0.22 \mu \mathrm{m}$ disposable LC filter disks. The analysis was carried out in a Dionex Ultimate 3000 UPLC system (Thermo Scientific, San Jose, CA, USA) equipped with a diode array detector (DAD; detection was performed using 280, 330 and $370 \mathrm{~nm}$ as preferred wavelengths) coupled to an electrospray ionization mass detector (ESI-MS) (Linear Ion Trap LTQ XL, Thermo Finnigan, San Jose, CA, USA) (Bessada et al., 2016). Chromatographic separation was achieved with a Waters Spherisorb S3 ODS-2C18 (3 $\mu \mathrm{m}$, $4.6 \mathrm{~mm} \times 150 \mathrm{~mm}$, Waters, Milford, MA, USA) column thermostated at $35{ }^{\circ} \mathrm{C}$. The solvents used were: (A) $0.1 \%$ formic acid in water, (B) acetonitrile. The elution gradient established was isocratic 15\% B (5 $\mathrm{min}), 15 \%$ B to $20 \%$ B (5 min), $20-25 \%$ B (10 $\mathrm{min}), 25-35 \%$ B (10 $\mathrm{min}), 35-50 \% \mathrm{~B}$ (10 $\mathrm{min}$ ), and re-equilibration of the column, using a flow rate of $0.5 \mathrm{~mL} / \mathrm{min}$. MS detection was performed in negative mode. Nitrogen served as the sheath gas (50 psi); the system was operated with a spray voltage of $5 \mathrm{kV}$, a source temperature of $325{ }^{\circ} \mathrm{C}$, a capillary voltage of $-20 \mathrm{~V}$. The tube lens offset was kept at a voltage of $-66 \mathrm{~V}$. The full scan covered the mass range from $\mathrm{m} / \mathrm{z} 100-1500$. The collision energy used was 35 (arbitrary units). Data were acquired using the Xcalibur $^{\circledR}$ data system (Thermo Finnigan, San Jose, CA, USA). Compounds were identified by comparison of their retention time, MS characteristics (molecular ion and $\mathrm{MS}^{\mathrm{n}}$ fragmentation pattern) and UV-vis spectrum, with those of standard compounds, when available; otherwise, compounds were identified comparing the obtained information with available data reported in the literature. For quantitative analysis, and external standard quantification was applied in which a calibration curve for each available phenolic standard was constructed based on the most appropriate UV-Vis signal [gallic acid $\left(\mathrm{y}=131538 \mathrm{x}+292163 ; \mathrm{R}^{2}=0.9969 ; \mathrm{LOD}=0.28 \mu \mathrm{g} / \mathrm{mL}\right.$; $\mathrm{LOQ}=0.87 \mu \mathrm{g} / \mathrm{mL}) ;$ protocatechuic acid $(\mathrm{y}=214168 \mathrm{x}+27102$; $\mathrm{R}^{2}=0.9999 ; \mathrm{LOD}=0.14 \mu \mathrm{g} / \mathrm{mL}$; LOQ $\left.=0.52 \mu \mathrm{g} / \mathrm{mL}\right)$; chlorogenic acid $\left(\mathrm{y}=168823 \mathrm{x}-161172 ; \mathrm{R}^{2}=0.999 ; \mathrm{LOD}=0.20 \mu \mathrm{g} / \mathrm{mL}\right.$; LOQ $=0.68 \mu \mathrm{g} / \mathrm{mL}) ;$ caffeic acid $(\mathrm{y}=388345 \mathrm{x}+406369$; $\left.\mathrm{R}^{2}=0.994 ; \mathrm{LOD}=0.19 \mu \mathrm{g} / \mathrm{mL} ; \mathrm{LOQ}=0.65 \mu \mathrm{g} / \mathrm{mL}\right) ; p$-hydroxybenzoic acid $\left(\mathrm{y}=208604 \mathrm{x}+173056 ; \mathrm{R}^{2}=0.9995\right.$; $\mathrm{LOD}=0.51 \mu \mathrm{g} / \mathrm{mL} ; \mathrm{LOQ}=1.31 \mu \mathrm{g} / \mathrm{mL})$; ferulic acid $(\mathrm{y}=633126 \mathrm{x}-$ $185462 ; \mathrm{R}^{2}=0.999 ; \mathrm{LOD}=0.20 \mu \mathrm{g} / \mathrm{mL} ; 1.01 \mu \mathrm{g} / \mathrm{mL}$ ); and apigenin-6$C$-glucoside (y = 107025x $+61531 ; \mathrm{R}^{2}=0.9989 ; \mathrm{LOD}=0.19 \mu \mathrm{g} / \mathrm{mL}$; $\mathrm{LOQ}=0.63 \mu \mathrm{g} / \mathrm{mL}$ )]; when no commercial standards were available, quantification was based on calibrations generated with the most similar standard (assuming that the molar absorptivity of the identified compound is the same as that of the corresponding free standard molecule). Results were given as mg per $\mathrm{g}$ of extract.

\subsection{Assessment of bioactive properties}

\subsubsection{Antioxidant activity}

The cell-based assays for the inhibition of oxidative haemolysis (OxHLIA) and formation of thiobarbituric acid reactive substances (TBARS) were performed using sheep erythrocytes and porcine brain cells as subtracts, respectively, following methods previously described (Lockowandt et al., 2019). Results were given as $\mathrm{IC}_{50}$ values $(\mu \mathrm{g} / \mathrm{mL})$ at $\Delta t 60$ and $120 \mathrm{~min}$ (for OxHLIA) and as $\mathrm{EC}_{50}$ values $(\mu \mathrm{g} / \mathrm{mL}$ ) (for TBARS).

\subsubsection{Cytotoxic and hepatotoxic activities}

The extracts were tested against four human tumour cell lines: MCF7 (breast adenocarcinoma), NCI-H460 (non-small cell lung cancer), HeLa (cervical carcinoma), and HepG2 (hepatocellular carcinoma), acquired from Leibniz Institute DSMZ (German Collection of Microorganisms and Cell Cultures). Cells were routinely maintained as adherent cell cultures in RPMI-1640 medium containing 10\% heat-inactivated FBS (MCF-7 and NCI-H460) and $2 \mathrm{mM}$ glutamine or in DMEM supplemented with $10 \% \mathrm{FBS}, 2 \mathrm{mM}$ glutamine, $100 \mathrm{U} / \mathrm{mL}$ penicillin, and $100 \mathrm{mg} / \mathrm{mL}$ streptomycin (HeLa and HepG2), at $37{ }^{\circ} \mathrm{C}$ and with $5 \%$ $\mathrm{CO}_{2}$. For the non-tumour cell line (PLP2), a cell culture previously prepared from freshly harvested porcine liver was used to determine hepatotoxicity (Pereira, Calhelha, Barros, \& Ferreira, 2013). The cells were sub-cultured and plated in 96-well plates and allowed to attach for $24 \mathrm{~h}$. Cells were then treated for $48 \mathrm{~h}$ with different extract concentrations $(6.25-400 \mu \mathrm{g} / \mathrm{mL})$. Following incubation, the adherent cells were fixed by adding cold $10 \%$ trichloroacetic acid $(100 \mu \mathrm{L})$ and incubated for $60 \mathrm{~min}$ at $4{ }^{\circ} \mathrm{C}$. Plates were then washed with deionized water; a sulforhodamine B (SRB) solution $(0.1 \%$ in $1 \%$ acetic acid, $100 \mu \mathrm{L}$ ) was then added to each plate well and incubated for $30 \mathrm{~min}$ at room temperature. Unbound SRB was removed by washing with $1 \%$ acetic acid and bound SRB was solubilized with $10 \mathrm{mM}$ Tris $(200 \mu \mathrm{L})$. The absorbance was measured at $540 \mathrm{~nm}$ (Vaz et al., 2010). Ellipticine was used as positive control. Results were expressed as $\mathrm{GI}_{50}$ values $(\mu \mathrm{g} /$ $\mathrm{mL}$ ), i.e., extract concentration that inhibits $50 \%$ of the net cell growth.

\subsubsection{Nitric oxide (NO) inhibition activity}

The lipopolysaccharide (LPS)-induced NO production by a murine macrophage cell line (RAW 264.7) was determined as nitrite concentration in the culture medium (Sobral et al., 2016). Dexamethasone was used as a positive control; negative controls were performed without LPS. NO production was determined using a Griess Reagent System kit containing sulfanilamide, $\mathrm{N}$-1-naphthylethylenediamine dihydrochloride and nitrite solutions. Results were expressed as $\mathrm{EC}_{50}$ values $(\mu \mathrm{g} / \mathrm{mL})$.

\subsubsection{Antimicrobial activity}

The extracts were screened against the Gram-positive bacteria Bacillus cereus (food isolate), Staphylococcus aureus (ATCC 6538), and Enterococcus faecalis (ATCC 19433), and the Gram-negative bacteria Escherichia coli (ATCC 35210), Proteus mirabilis (clinical isolate), and Salmonella enterica serovar Typhimurium (ATCC 13311). The microfungi Aspergillus ochraceus (ATCC 12066), Aspergillus niger (ATCC 6275), Penicillium aurantiogriseum (food isolate), and Penicillium funiculosum (ATCC 36839) were also tested. Microorganisms were obtained from the Mycological Laboratory, Institute for Biological Research "Sinisa Stanković", University of Belgrade, Serbia. The assay was carried out by a microdilution method (Soković, Glamočlija, Marin, Brkić, \& van Griensven, 2010; Soković \& van Griensven, 2006). The extracts were dissolved in 5\% DMSO containing 0.1\% Tween $80(v / v)(5000-5 \mu \mathrm{g} /$ $\mathrm{mL}$ ) and added in tryptic soy broth (TSB) medium $(100 \mu \mathrm{L})$ with bacterial/fungi inoculum $\left(1.0 \times 10^{4} \mathrm{CFU}\right.$ per well). The lowest concentrations without visible growth were defined as concentrations that 
completely inhibited bacterial growth (MICs). MICs obtained from the susceptibility testing of various bacteria/fungi to tested extracts were also determined by a colorimetric microbial viability assay based on reduction of INT ( $p$-iodonitrotetrazolium violet) colour and compared with positive controls for each strain. Minimum bactericidal/fungicidal concentrations (MBC/MFC) were determined by serial sub-cultivation of $2 \mu \mathrm{L}$ into plates containing $100 \mu \mathrm{L}$ of broth per well and further incubation for $24 \mathrm{~h}$. The lowest concentration with no visible growth was defined as the MBC/MFC, indicating $99.5 \%$ killing of the original inoculum. The optical density of each well was measured at $655 \mathrm{~nm}$ in a Microplate manager 4.0 (Bio-Rad Laboratories) and compared with a blank (broth medium plus diluted compounds) and the positive controls (streptomycin and ampicillin were used for bacteria inhibition, while ketoconazole and bifonazole were used for fungal inhibition).

\subsection{Statistical analysis}

Data represent the mean ( \pm standard deviation) of three independent experiments, each performed in triplicate $(n=9)$. All statistical tests were performed at a 5\% significance level using SPSS Statistics software (IBM SPSS Statistics for Windows, Version 22.0. Armonk, NY: IBM Corp.). Differences among treatments were analysed using one-way analysis of variance (ANOVA). The fulfilment of the ANOVA requirements, specifically the normal distribution of residuals and the homogeneity of variance, was tested by means of the Shapiro Wilk's and the Levene's tests, respectively. All dependent variables were compared using Tukey's honestly significant difference (HSD) or Tamhane's T2 multiple comparison tests, when homoscedasticity was verified or not, respectively.

\section{Results and discussion}

\subsection{Phenolic compounds in rice and sunflower side-streams}

The characterization of polyphenols diversity in plant extracts is a subject of interest that is continuously addressed using each time updated techniques with higher detection sensitivities and resolutions (Weber \& Passon, 2019; Zoumpoulakis, Sinanoglou, Siapi, Heropoulos, \& Proestos, 2017). Herein, by using LC-DAD/ESI-MS ${ }^{\mathrm{n}}$, we performed a characterization of phenolic compounds in three crop side-streams, $\mathrm{SH}$, RH and RS (Table 1). The phenolic profiles are shown in Fig. S1.

RH contained one unidentified phenolic substance, while RS presented various monophenolics, their derivatives and a glycoside derivative of the flavone apigenin (4',5,7-trihydroxyflavone) (Table 1). Among the phenolic acids that were identified in rice, the hydroxybenzoic acids (gallic acid and vanillic acid) were found in the crop residue. Though, protocatechuic, $p$-hydroxybenzoic and syringic acids that were reported in rice plants (Ding et al., 2019), these compounds were not detected in the crop side-streams. Regarding hydroxycinnamic acids, only ferulic acid derivatives were found while those reported in rice like caffeic, $p$-coumaric and sinapic acids were not detected (McDonough, Rooney, \& Serna-Saldivar, 2000). In contrast, SH presented eleven phenolic compounds from which seven were identified (Table 1). Gallic acid was the compound found in higher amounts, followed by caffeoylquinic acids, protocatechuic acid, and caffeic acid and its derivatives. In general, the SH had a higher content of phenolic compounds than the RS (Fig. 1 and Table S1). Zoumpoulakis et al. (2017) found a lower content of phenolic substances in the sunflower husk in comparison with the sunflower seeds. The chlorogenic acid was the main compound which appears in the form of complexes or bound to proteins.

The different phenolic profile present in the crop side-streams could be related to other factors such as, the crop variety, the agronomic aspects, the industrial process and preservation conditions of the material or the extraction methods. However, this characterization was important to reveal the substrate composition in order to know the modifications produced when these side-materials underwent to SSF with Mk and Dk strains of $P$. sapidus.

\subsection{Solid-state fermentation of rice and sunflower side-streams with $P$. Sapidus}

As shown in Fig. 1, the whole content of phenolic compounds in the crops side-streams was reduced after SSF with $P$. sapidus. The tendency was rather similar with both $P$. sapidus strains ( $\mathrm{Mk}$ and $\mathrm{Dk}$ ) and it continues when the fermentation was extending for 55-65 days after the fructification phase (spent mushroom substrate; SMS). Nevertheless, the statistical analysis showed that, in the case of $\mathrm{SH}$, the

Table 1

Identification of phenolic compounds in rice and sunflower side-streams. Retention time (Rt), wavelengths of maximum absorption in the UV-vis region ( $\lambda$ max), pseudomolecular and $\mathrm{MS}^{2}$ fragment ions and relative abundance in brackets.

\begin{tabular}{|c|c|c|c|c|c|}
\hline Peak & Rt (min) & $\lambda_{\max }(\mathrm{nm})$ & {$[\mathrm{M}-\mathrm{H}]^{-}(m / z)$} & $\mathrm{MS}^{2}$ fragments $(m / z)$ & Tentative identification \\
\hline \multicolumn{6}{|c|}{ Sunflower seed hulls } \\
\hline 1 & 4.75 & 270 & 169 & $125(100)$ & Gallic acid \\
\hline 2 & 5.63 & 262,294 & 153 & $109(100)$ & Protocatechuic acid \\
\hline 3 & 6.68 & 324 & 353 & 191(84), 179(29), 173(10 0), 161(11), 135(5) & 4-O-Caffeoylquinic acid \\
\hline 4 & 7.67 & 326 & 353 & 191(100), 179(54), 173(10), 161(5), 135(5) & 5-O-Caffeoylquinic acid \\
\hline 5 & 9.61 & 320 & 179 & $135(100)$ & Caffeic acid \\
\hline 6 & 14.45 & 322 & - & 179(10), 135(100) & Caffeic acid derivative \\
\hline 7 & 17.81 & 324 & 225 & 179(100), 135(5) & Caffeic acid derivative \\
\hline 8 & 18.74 & 264 & 251 & 233(21), 205(11), 189(1 0 0) & Unknown \\
\hline 9 & 19.18 & 264 & 577 & 241(5), 167(100), 159(5), 139(5) & Unknown \\
\hline 10 & 22.22 & 275 & 195 & 151(100), 135(5), 109(3), 107(3) & Unknown \\
\hline 11 & 27.02 & 283 & 559 & $241(100), 167(5)$ & Unknown \\
\hline \multicolumn{6}{|c|}{ Rice husks } \\
\hline 1 & 15.47 & 298,306 & 159 & 113(100) & Unknown \\
\hline \multicolumn{6}{|c|}{ Rice straw } \\
\hline 1 & 4.61 & 270 & 169 & $125(100)$ & Gallic acid \\
\hline 2 & 9.49 & 266 & 167 & $152(100), 123(5)$ & Vanillic acid \\
\hline 3 & 11.69 & 275 & 209 & 194(87), 165(81), 150(100), 121(29), 106(6) & Unknown \\
\hline 4 & 14.23 & 316 & 237 & 193(100), 179(57), 149(61), 134(27) & Ferulic acid derivative \\
\hline 5 & 14.76 & 308 & 237 & 193(100), 179(57), 149(61), 134(27) & Ferulic acid derivative \\
\hline 6 & 15.34 & 308 & 237 & 193(100), 179(57), 149(61), 134(27) & Ferulic acid derivative \\
\hline 7 & 17.40 & 326 & 533 & 515(33), 473(54), 443(100), 383(18), 353(15) & Apigenin- $C$-glycoside derivative \\
\hline 8 & 18.69 & 286 & 261 & 187(100), 169(8), 125(38) & Gallic acid derivative \\
\hline
\end{tabular}




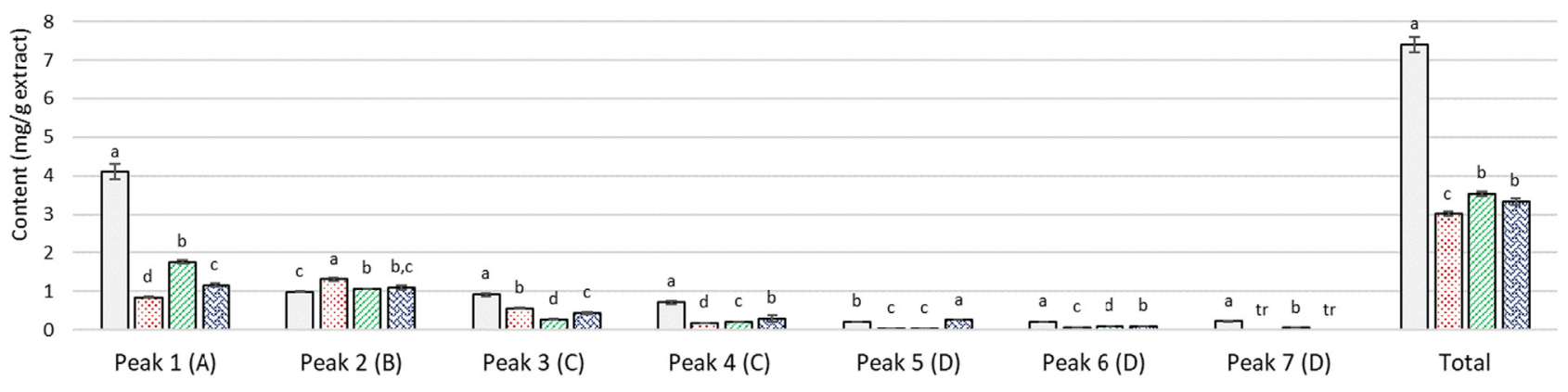

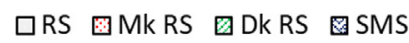

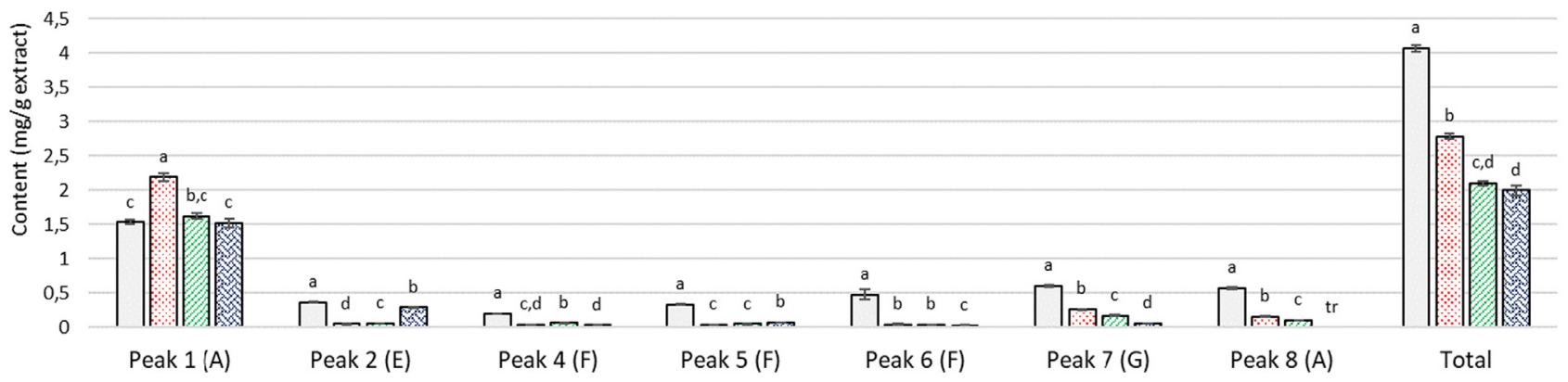

Fig. 1. Content of phenolic compounds in (A) sunflower seed hulls (SH) and (B) rice straw (RS) after SSF with dikaryotic (Dk) and monokaryotic (Mk) strains of $P$. sapidus Dk3174. Spent mushroom substrate (SMS; RS or SH) obtained after fructification of the dikaryotic strain. Letters in brackets correspond to the calibration curves used for quantification: A- gallic acid ( $\left.\mathrm{y}=131538 \mathrm{x}+292163 ; \mathrm{R}^{2}=0,9969\right)$; B- protocatechuic acid $\left(\mathrm{y}=214168 \mathrm{x}+27102\right.$; $\left.\mathrm{R}^{2}=0.9999\right)$; C- chlorogenic acid ( $\left.\mathrm{y}=168823 \mathrm{x}-161172 ; \mathrm{R}^{2}=0.999\right) ; \mathrm{D}$ - caffeic acid $\left(\mathrm{y}=388345 \mathrm{x}+406369 ; \mathrm{R}^{2}=0.994\right) ; \mathrm{E}-\mathrm{p}$-hydroxybenzoic acid $\left(\mathrm{y}=208604 \mathrm{x}+173056 ; \mathrm{R}^{2}=0.9995\right) ;$ F- ferulic acid ( $\left.\mathrm{y}=633126 \mathrm{x}-185462 ; R^{2}=0.999\right)$; and G- apigenin-6-C-glucoside (y = 107025x $\left.+61531 ; R^{2}=0.9989\right)$. tr: traces. Within each peak group, different letters over bars indicate statistically significant differences $(p<0.05)$ between treatments. See Table 1 for peak identification.

decrease in the total content of phenolic compounds was more pronounced in the case of the Mk, whereas in the case of RS, the decrease was greater in the treatments with the Dk (Dk and SMS). It is important to note that Mk strains are not able to form fruiting bodies, for this reason only the Dk strain was assayed for longer times. Since phenolic compounds consist of several chemical subgroups such as phenylpropanoids, flavonoids and polymers such as tannins, the modifications produced by SSF might derivate in a more bioactive blend (Bhanja Dey \& Kuhad, 2014). Previous studies pointed out that different white rot fungi species such as Phanerochaete chrysosporium, Phlebia floridensis, Lentinula edodes, or Pleurotus ostreatus showed a positive enhancement of the total phenolic content, sterols, protein digestibility and antioxidant activities after 15 to 60 days of SSF, using wheat straw, paddy straw, seeds of fresh black beans and oat, as substrates (Espinosa-Páez et al., 2017; Sharma \& Arora, 2014; Wang et al., 2018). However, that was not the case for the phenolic fractions recovered after the SSF of rice and sunflower side-streams by $P$. sapidus strains ( $\mathrm{Mk}$ and $\mathrm{Dk}$ ). The results indicated that a number of factors can impact on the production, availability and bioactivities of the compounds, like the type and composition of plat material, the fungus species and its associate enzymes, the genotype by environmental interaction, the fermentation times and culture conditions (Martins et al., 2011).

The individual phenolics compounds found in the fermented crop side-streams were quantified and the pattern shows that most of them were reduced after SSF with both strains of P. sapidus (Fig. 1 and Table S1). The major phenolic compound in these lignocellulosic materials was gallic acid; it was interesting to note that this acid was degraded by the fungus in $\mathrm{SH}$, while its concentration was not significantly modified when the Dk grew on RS, including the long-term cultures (SMS) (Fig. 1). On the other hand, higher levels of this soluble phenolic compound were quantified in RS fermented with the Mk strain. These observations may be related to the microorganisms' capacity to secrete different enzymes and thus degrade the cell wall structure and release different bound phenolics during fermentation, such as gallic acid (Yin et al., 2018). Other possible explanation is related to the complexity of the lignocellulosic biomass and the presence of other constitutes (e.g. silica in $\mathrm{RS}$ or $\mathrm{RH}$ ) that can hinder the process for fungal bioconversion of the plant components (Bhanja Dey, Chakraborty, Jain, Sharma, \& Kuhad, 2016). Regarding the second more abundant phenolic compound of $\mathrm{SH}$, the protocatechuic acid, its concentration was not significantly modified by the long-term culture (SMS), but it was increased by the Mk fermentation. This behaviour could be explained by the interaction between the fungal strains ( $\mathrm{Mk}$ and $\mathrm{Dk}$ ) and the substrates used for SSF, since the biomass components can induce the production of different extracellular enzymes which can act on the lignocellulosic material and enhance the release of desire compounds or contribute with structural modifications (Bhanja Dey et al., 2016; Martins et al., 2011; Wang et al., 2018). Regarding the effect on other compounds, the contents of 4-O- and 5-O-caffeoylquinic acids and ferulic acid derivatives also decreased with the applied treatments, while caffeic acid was detected in higher amount in the long-term culture.

It is important to note that the different enzymes responsible for the biotransformation of lignocellulosic materials are mainly produced by fungi, since these have a hydrolytic system that produces hydrolases able to degrade polysaccharides, and an oxidative ligninolytic system that degrades lignin and opens phenyl rings, increasing the free phenolic content (Sánchez et al., 2009). Therefore, the action of these enzymes plays an important role in the mobilization of bioactive constituents during SSF and may cause a decrease or increase in the amount of phenolic compounds, with a consequent impact on bioactive properties (Martins et al., 2011).

Phenolic compounds are known to present pharmacological activities like antioxidant, anti-proliferative, antimicrobial, antiviral, and so on (Dykes \& Rooney, 2007; Perez-Vizcaino \& Fraga, 2018). The 
antioxidant capacity of these secundary metabolites can be attributed to its ability to donate a hydrogen atom from the aromatic hydroxyl group to a free radical and/or to support an unpaired electron in the aromatic structures (Dai \& Mumper, 2010). Additionally, the biological activities of natural extracts could be ascribed to a mixture of these and other bioactive compounds (which can interact through additive or synergistic effects) instead of a specific individual substance. With this argument, the combined extracts prepared from the materials obtained after SSF were studied for antioxidant, cytotoxic, NO-inhibition and antimicrobial activities.

\subsection{Biological activities of SSF extracts: antioxidant, cytotoxic, NO-} inhibition and antimicrobial activities

Most plant-based materials have phenolic compounds that affect their appearance and the oxidative stability. In cereals, these compounds are mainly located in the pericarp and can be concentrated by decorticating the grains to produce bran that can be used as food additives to increase the nutraceutical properties. Actually, there is a high correlation between the phenolic content and the antioxidant activity (Dykes \& Rooney, 2007). Under this perspective and considering the quantification of phenolic compounds showed above (Fig. 1), it is expected that SSF will reduce the antioxidant activity of the fermented cereal side-streams. Fig. 2 and Table S2 show the lower antioxidant capacity of the fermented extracts regarding the antioxidant activity displayed by the original lignocellulosic substrates. This activity was assessed by the TBARS and OxHLIA cell-based assays. The first assay allows to measure the extracts capacity to inhibit the formation of thiobarbituric acid reactive substances (TBARS), such as malondialdehyde, which are generated from the ex vivo decomposition of lipid peroxidation products resulting from the oxidation of the porcine brain cell membranes. In turn, the OxHLIA assay provides information on the extract capacity to protect the erythrocyte membranes from oxidative haemolysis. In this method, the erythrocytes were subjected to the haemolytic action of hydrophilic (peroxyl) radicals that resulted from the thermal decomposition of AAPH and, subsequently, to the action of lipophilic (alkyl) radicals generated through a lipid peroxidation phenomenon as a result of the initial attack (Prieto \& Vázquez, 2014). This ex vivo erythrocytes system offers near-in vivo conditions as the peroxyl radicals generated in the in vitro system are also found in the human body (Takebayashi, Iwahashi, Ishimi, \& Tai, 2012). Therefore, both methods are useful biological systems for measuring the antioxidant activity of natural extracts compared to chemical methods that do not extrapolate the performance of the sample in vivo (LópezAlarcón \& Denicola, 2013; Zhong, 2015).

Cereals, especially those that do not have tannins or pigments, such as white rice, generally do not exhibit notable antioxidant activities. In contrast, cereals that have condensed tannins have reduced the nutritional efficiency by reducing the digestion of polysaccharides. However, the in vitro antioxidant activity does not give information about the bioavailability or metabolism of these extracts in biological systems (Dykes \& Rooney, 2007). Results indicated that $P$. sapidus could present an interesting biocatalyst for the SSF of other agro-industrial sidestreams with high polyphenolic and anti-nutritional compounds content (Torres-León et al., 2018). Previous reports indicated that the process was efficient to recover other value-added products with high demand in the food industry such as enzymes, sterols, and protein rich material (Espinosa-Páez et al., 2017; Martins et al., 2011; Postemsky et al., 2019; Sharma \& Arora, 2014; Wang et al., 2018).

In contrast to $P$. sapidus fermentation, the extraction of phenolic compounds was improved by SSF of wheat using the edible fungus Rhizopus oryzae RCK2012, and the extracts possessed higher antioxidant activity in vitro (ABTS and DPPH methods) as well as in vivo (Saccharomyces cerevisiae method) in comparison with the activity displayed by the substrate (Bhanja Dey \& Kuhad, 2014). Similar results were reported for the extracts obtained after SSF of agro-industrial side-

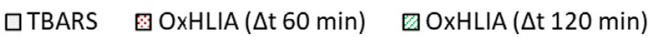

A

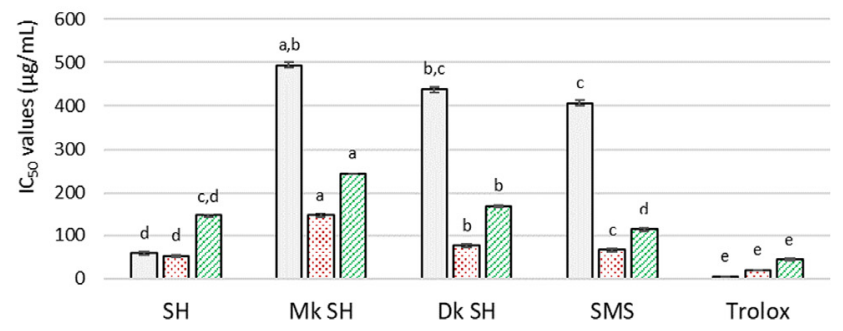

口TBARS O OXHLIA $(\Delta \mathrm{t} 60 \mathrm{~min}) \quad \square \mathrm{OxHLIA}(\Delta \mathrm{t} 120 \mathrm{~min})$

B

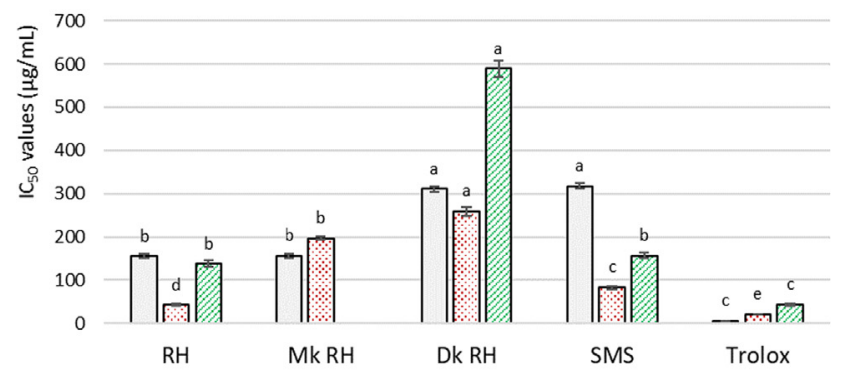

口TBARS ⿴囗⿱一一) OXHLIA $(\Delta \mathrm{t} 60 \mathrm{~min}) \quad \square \mathrm{OXHLIA}(\Delta \mathrm{t} 120 \mathrm{~min})$

C

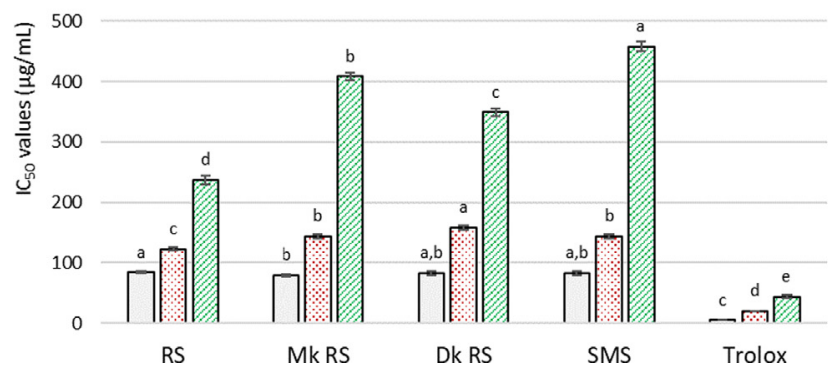

Fig. 2. Antioxidant activity of the extracts obtained from (A) sunflower seed hulls (SH), (B) rice husks (RH) and (C) rice straw (RS) after SSF with dikaryotic (Dk) and monokaryotic (Mk) strains of $P$. sapidus Dk3174. Spent mushroom substrate (SMS; RS, RH or SH) obtained after fructification of the dikaryotic strain. For each antioxidant activity assay, different letters over bars indicate statistically significant differences $(p<0.05)$ between treatments.

streams using different white rot fungal species, such as $P$. ostreatus, $P$. chrysosporium or P. floridensis (Espinosa-Páez et al., 2017; Sharma \& Arora, 2014). The extraction of phenolic compounds through fermentation processes was demonstrated to be an efficient bioprocess in comparison with the extraction with organic solvents. However, during fermentation, phenolic compounds are either produced by microorganisms and released from the substrate materials. Although fermentation technology is an important tool to increased phenolic compounds for functional food production or pharmaceuticals, a broad toxicological characterization is needed before the validation of these extracts for human consumption and/or health benefits (Bhanja Dey et al., 2016). In addition, it was reported that the influence of other parameters such as fermentation time, enzymatic profile and the release of bound compounds, affected the bioactive compounds recovery and their bioactivities (Torres-León et al., 2019; Zhang et al., 2017).

The fungi Aspergillus oryzae and A. awamori were successfully used in SSF to increase the phenolic content and antioxidant properties of wheat grains (Bhanja, Kumari, \& Banerjee, 2009). SSF soybean sidestreams by Trichoderma harzianum also showed higher antioxidant activity than unfermented substrate and it was related to the increment of the relative concentration of phenolic acids and flavonoids during the process (Singh, Singh, Singh, \& Nautiyal, 2010). The increment of 


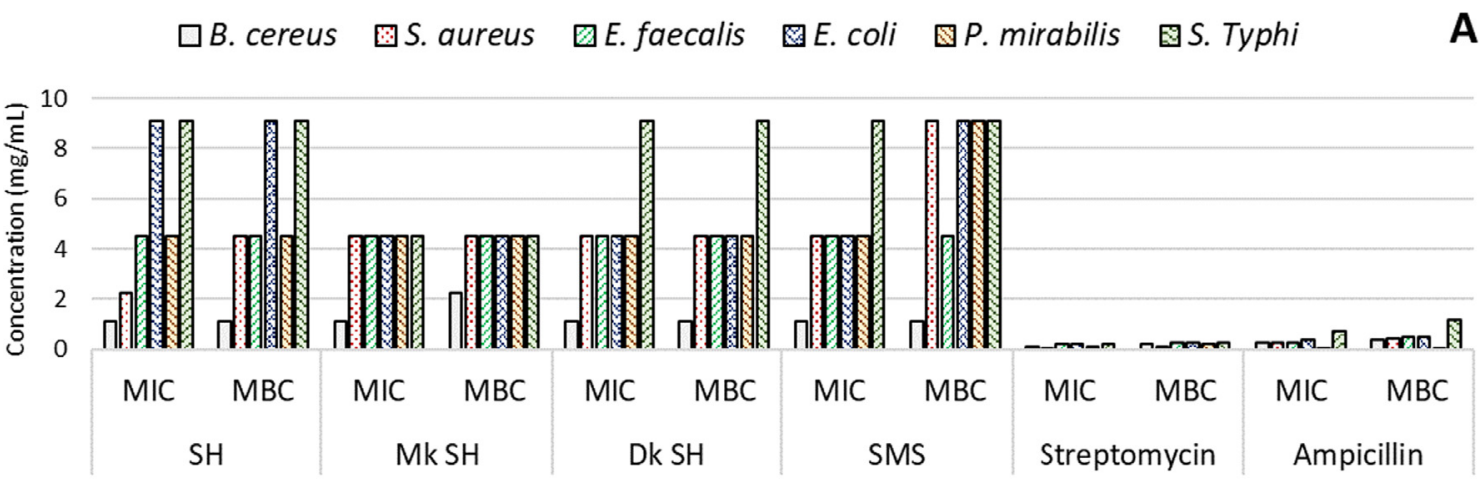

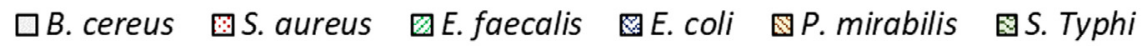

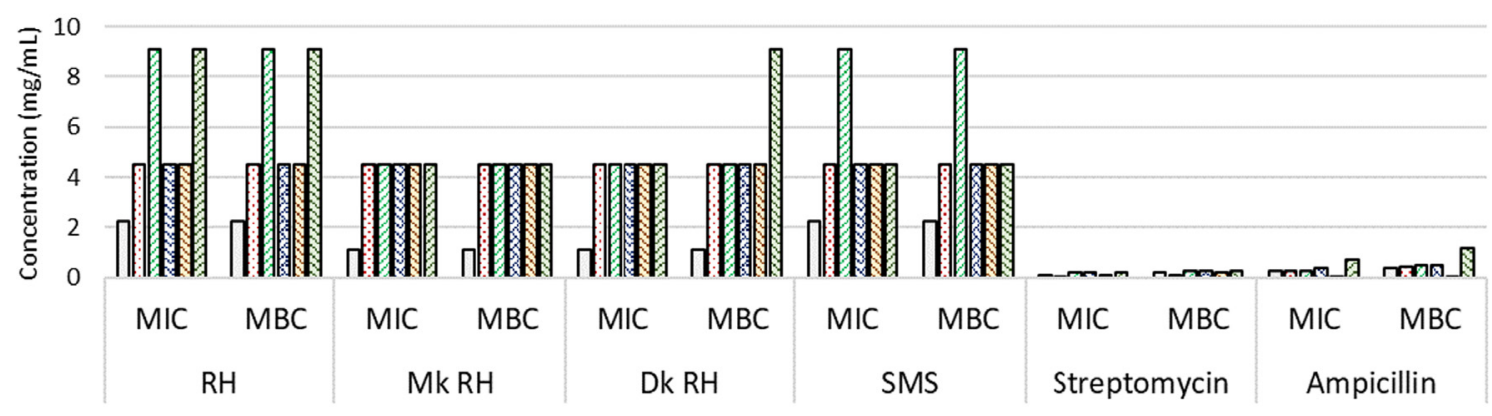

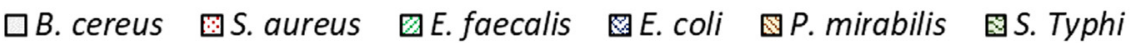

C

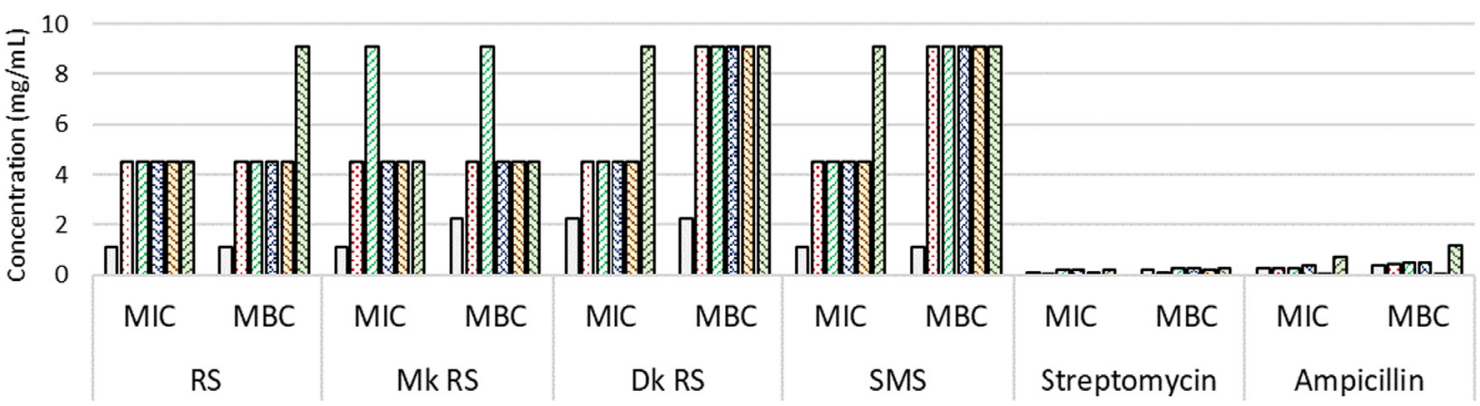

Fig. 3. Antifungal activity of the extracts obtained from (A) sunflower seed hulls (SH), (B) rice husks (RH) and (C) rice straw (RS) after SSF with dikaryotic (Dk) and monokaryotic (Mk) strains of P. sapidus Dk3174. Spent mushroom substrate (SMS; RS, RH or SH) obtained after fructification of the dikaryotic strain.

phenolic compounds by SSF of Vigna radiata (also known as green beans) with Rhizopus oligosporus has also been demonstrated (Randhir \& Shetty, 2007). This antioxidant activity enhancement contributed to the $\alpha$-amylase inhibition (which is relevant for the diabetes controlling), as well as for the inhibition of the Helicobacter pylori growth (linked to peptic ulcer management).

In this study, the three-crop side-streams and the resulting fermented materials were tested against tumour (MCF-7 - breast adenocarcinoma, NCI-H460 - non-small cell lung cancer, HeLa - cervical carcinoma, and HepG2 - hepatocellular carcinoma) and non-tumour (PLP2 - porcine liver primary cells) cell lines in order to evaluate possible cytotoxicity. The extract obtained from SH (which had the highest content of phenolic compounds) showed cytotoxic effects against HeLa tumour cells ( $\mathrm{GI}_{50}$ value of $292 \pm 18 \mu \mathrm{g} / \mathrm{mL}$ ), whereas the remaining samples had $\mathrm{GI}_{50}$ values $>400 \mu \mathrm{g} / \mathrm{mL}$ (Table S3). Thus, these results might be related to the lower content of phenolic compounds found especially in the fermented samples, as it was mention before (Fig. 1). Interestingly, the normal PLP2 cells were not affected by any of the tested extracts. In turn, none of the samples demonstrated anti-inflammatory activity through the inhibition of NO production in LPS- stimulated murine macrophage RAW 264.7 cells $\left(\mathrm{EC}_{50}\right.$ values $>400$ $\mu \mathrm{g} / \mathrm{mL}$ ) (Table S3).

The antibacterial activity of the extracts was assessed using Grampositive bacteria (Bacillus cereus, Staphylococcus aureus and Enterococcus faecalis) and Gram-negative bacteria (Escherichia coli, Proteus mirabilis and Salmonella Typhimurium). In all cases, streptomycin and ampicillin (positive controls) showed values of minimum inhibitory concentration (MIC) and minimum bactericidal concentration (MBC) $<1 \mathrm{mg} / \mathrm{mL}$, with the only exception of $S$. Typhimurium whose MBC for ampicillin rise up to $1.2 \mathrm{mg} / \mathrm{mL}$ (Fig. 3 and Table S4). On the other hand, the rice and sunflower side-streams and the fermented materials presented MIC and $M B C$ values $>1 \mathrm{mg} / \mathrm{mL}$, indicating that all assayed bacteria exhibited a lower sensitive to the tested extracts. As it was pointed out elsewhere, the activity of a given compound could be reduced or increased depending on its structural configuration. For example, the introduction of one or more hydroxyl or methoxy groups can decreased the antibacterial activity (Zygadlo et al., 2017). B. cereus was the most sensitive microorganism, while $S$. Typhimurium was, in relative terms, the most resistant (Fig. 3). However, the tested bacteria were affected differently depending on the crop side-stream and/or the SSF 


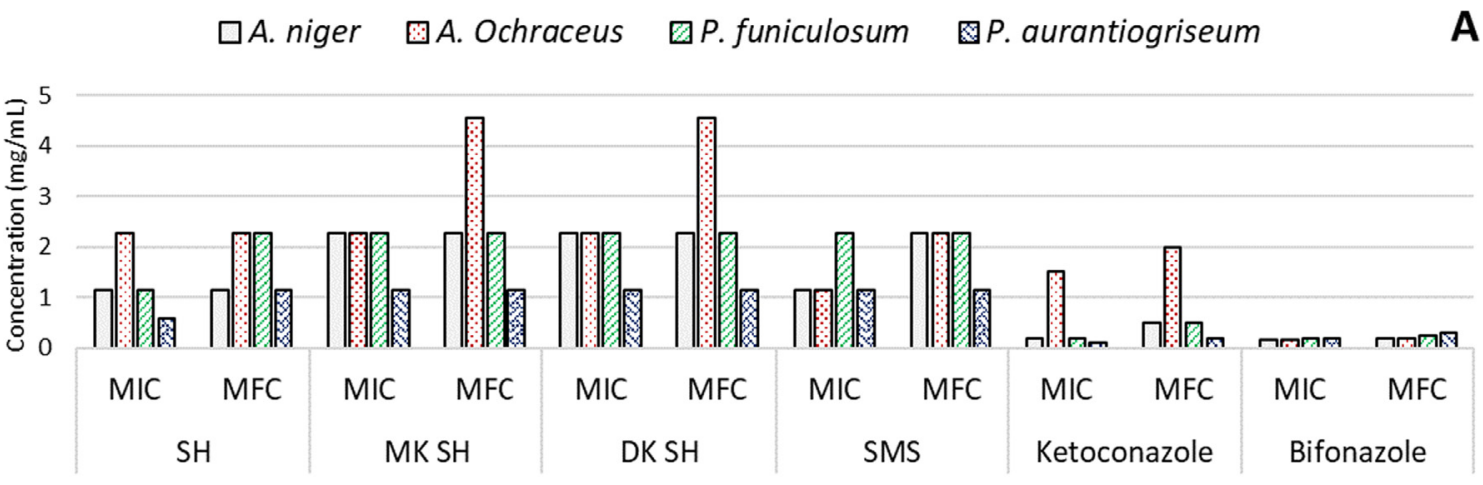

$\square$ A. niger A. Ochraceus $\square P$. funiculosum 圈 $P$. aurantiogriseum

B

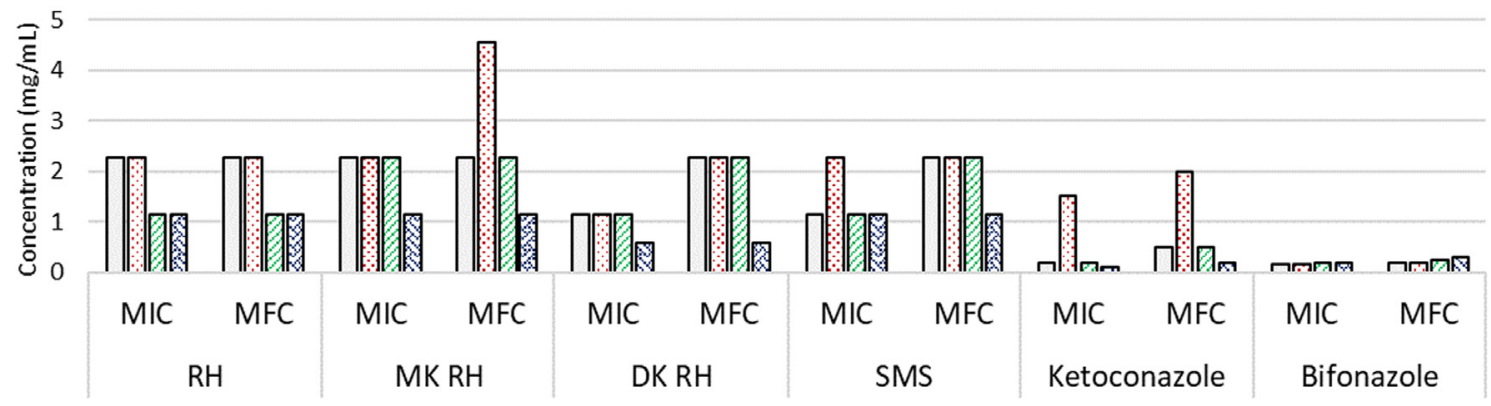

$\square$ A. niger $⿴$ A. Ochraceus $\square$ P. funiculosum $⿴ 囗$ P. aurantiogriseum

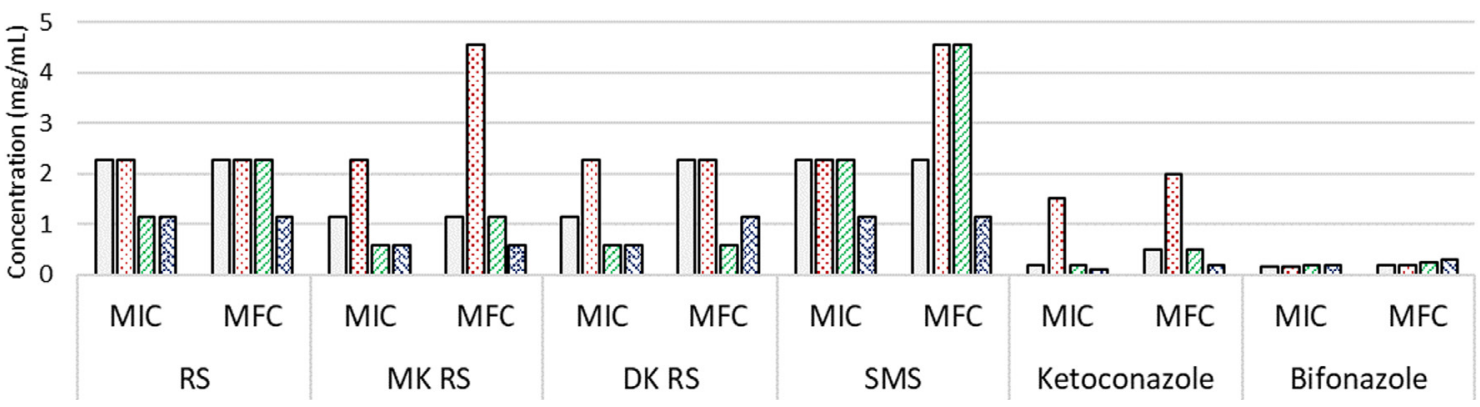

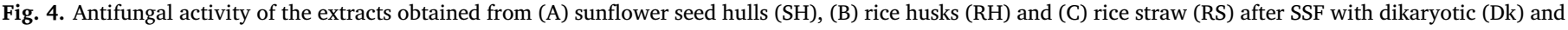
monokaryotic (Mk) strains of $P$. sapidus Dk3174. Spent mushroom substrate (SMS; RS, RH or SH) obtained after fructification of the dikaryotic strain.

conditions. As an example, the extracts of SSF of rice husk showed a slight tendency to increase the antimicrobial activity against $B$. cereus, E. faecalis and $S$. Typhimurium and, oppositely, the SSF extracts of rice straw showed a reduced activity against the same microorganisms.

The antifungal activity was assayed against collection strains of Aspergillus ochraceus, Aspergillus niger, Penicillium aurantiogriseum and Penicillium funiculosum. The positive controls ketoconazole and bifonazole gave values of MIC and minimum fungicidal concentration (MFC) $\leq 0.5 \mathrm{mg} / \mathrm{mL}$ (except for ketoconazole against A. ochraceus) (Fig. 4 and Table S5). On the other hand, the MIC and MFC values of all the samples (rise and sunflower side-streams and fermented materials) assayed against the microfungi were found $>0.5 \mathrm{mg} / \mathrm{mL}$, indicating that the phenolic extracts were weakly active against the tested microorganism. In relative terms, the Aspergillus strains were more resistant than Penicillium strains, being $P$. aurantiogriseum the more sensitive fungus to the assayed materials. However, in the case of $\mathrm{SH}$, there was a tendency for the fermented materials to present higher MICs and/or MFCs (Fig. 4), in agreement with the lower phenolic content of these sample materials. In the particular case of RS biomass, fermentation with $\mathrm{Mk}$ and $\mathrm{Dk}$ originated samples with higher antifungal activity against $P$. funiculosum, while the long-term culture (SMS) reduced this activity, comparatively with the original substrate.

Interestingly, bioactivity was also increased by SSF of stale rice using Cordyceps sinensis (Zhang, Lei, Lu, Lu, \& Chen, 2008). In a recent study, the SSF with $P$. chrysosporium caused the production of ligninolytic enzymes that released ferulic acid from the green coconut husk cell wall and, subsequently, vanillin was obtained with high yield by the ferulic acid conversion (Barbosa, Perrone, Vendraminido, \& Leite, 2008).

Although several fungi were found to increase the concentration of phenolic compounds during SSF, that is not the case of the genus Pleurotus, were several reports found a reduction in the aromatic ratio of several timbers like oak (Quercus castaneifolia) or beech wood (Fagus orientalis) (Bari et al., 2015; Karim et al., 2016). This preferential degradation is in agreement with the studies of Martínez, Camarero, Gutiérrez, Bocchini, \& Galletti, 2001, which showed that wheat lignin is selectively modified by Pleurotus eryngii, where the free phenolic ligninunits ( $p$-hydroxyphenyl, guaiacyl and syringyl) are preferentially removed in comparison with the etherified units of lignin.

Interestedly, in the last decades, many bioactive compounds have 
been isolated from fruiting bodies of basidiomycetes, including Pleurotus spp. However, the antitumor, antiviral, hepatoprotective bioactivities, were mainly related to macromolecules attached to the cell biomass like polysaccharides, ß-glucans, proteoglycans, lectins and terpenoids (Cohen, Persky, \& Hadar, 2002). On the other hand, considering the nowadays problems associated to morbidity and mortality of feedlot management, especially in calves, the proposal of boosting this edible fungus for upgrade the agricultural wastes could be widespread applied as animal fodder (Ghorai et al., 2009). Additional studies should be conducted in order to optimize the fermentation conditions and increase the bioactive compound production.

\section{Conclusion}

Both the dikaryotic and the monokaryotic strains of $P$. sapidus could be employed in SSF mode on rice and sunflower by-products in order to obtain a putative animal feed with reduced content in polyphenols. In general, these fermented materials displayed lower antioxidant and cytotoxic activities but no hepatotoxicity. The antimicrobial activity depended upon the substrate under analysis and the fermentation conditions. This study opens the way for the design of an animal feed where the content of polyphenols can be tailored so as to improve digestibility, but also to reduce the content of antinutritional factors in food. The method has potential to utilise recalcitrant lignocellulosic materials, thus contributing to efficient biomass recycling. In future studies it will be interesting to explore new applications of the fermented substrates in different sectors, including feed, food, and biomaterials.

\section{CRediT authorship contribution statement}

José Pinela: Data curation, Methodology, Investigation, Writing original draft, Writing - review \& editing. Alejandra B. Omarini: Conceptualization, Data curation, Methodology, Investigation, Writing - original draft, Writing - review \& editing. Dejan Stojković: Data curation, Methodology, Investigation. Lillian Barros: Conceptualization, Data curation, Formal analysis, Methodology, Investigation, Validation, Writing - review \& editing. Pablo D. Postemsky: Conceptualization, Methodology, Investigation, Writing original draft. Ricardo C. Calhelha: Formal analysis, Methodology, Investigation. Javier Breccia: Conceptualization, Investigation, Validation, Writing - original draft, Writing - review \& editing. Marcelo Fernández-Lahore: Conceptualization, Investigation, Validation, Writing - original draft, Writing - review \& editing. Marina Soković: Formal analysis, Methodology, Validation, Supervision. Isabel C.F.R. Ferreira: Conceptualization, Validation, Supervision, Writing - review \& editing.

\section{Declaration of Competing Interest}

The authors declare that they have no known competing financial interests or personal relationships that could have appeared to influence the work reported in this paper.

\section{Acknowledgements}

The authors are grateful to the Foundation for Science and Technology (FCT, Portugal) and FEDER under Programme PT2020 for financial support to CIMO (UID/AGR/00690/2019) and the research contracts of J. Pinela, R.C. Calhelha and L. Barros (national funding by FCT, through the institutional scientific employment program-contract). To FEDER-Interreg España-Portugal programme for financial support through the project 0377_Iberphenol_6_E. CONICET UNLPam project PIO2015 15CO. This work was partially supported by the Argentina-Germany Research Project MOPSACI (MINCyT-BMBFBioeconomy, 2017-2019), CYTED Network BIORRECER (316RT0507;
2016-2020), projects for Unidades Ejecutoras 2017 CERZOS-UNSCONICET), grants from Banco Interamericano de Desarrollo y Ministerio de Ciencia Tecnología e Innovación Productiva (BID PICT 2014-2414; BID PICT 2016-2095) and Consejo Federal de Ciencia y Tecnología (COFECyT ESPRO 2017). A.O. was supported as a Georg Forster Research Fellow by the Alexander von Humboldt Foundation.

\section{Appendix A. Supplementary material}

Supplementary data to this article can be found online at https:// doi.org/10.1016/j.foodres.2020.109094.

\section{References}

Barbosa, E. S., Perrone, D., Vendraminido, A. L. A., \& Leite, S. G. F. (2008). Vanillin production by Phanerochaete chrysosporium grown on green coconut agro-industrial husk in solid state fermentation. BioResources, 3(4), 1042-1050.

Bari, E., Nazarnezhad, N., Kazemi, S. M., Tajick Ghanbary, M. A., Mohebby, B., Schmidt O., \& Clausen, C. A. (2015). Comparison between degradation capabilities of the white rot fungi Pleurotus ostreatus and Trametes versicolor in beech wood. International Biodeterioration \& Biodegradation, 104, 231-237.

Bessada, S. M. F., Barreira, J. C. M., Barros, L., Ferreira, I. C. F. R., \& Oliveira, M. B. P. P. (2016). Phenolic profile and antioxidant activity of Coleostephus myconis (L.) Rchb.f.: An underexploited and highly disseminated species. Industrial Crops and Products, 89, 45-51.

Bhanja Dey, T., Chakraborty, S., Jain, K. K., Sharma, A., \& Kuhad, R. C. (2016). Antioxidant phenolics and their microbial production by submerged and solid state fermentation process: A review. Trends in Food Science \& Technology, 53, 60-74.

Bhanja Dey, T., \& Kuhad, R. C. (2014). Enhanced production and extraction of phenolic compounds from wheat by solid-state fermentation with Rhizopus oryzae RCK2012. Biotechnology Reports (Amsterdam, Netherlands), 4, 120-127.

Bhanja, T., Kumari, A., \& Banerjee, R. (2009). Enrichment of phenolics and free radical scavenging property of wheat koji prepared with two filamentous fungi. Bioresource Technology, 100(11), 2861-2866.

Bilal, M., \& Iqbal, H. M. N. (2019). Sustainable bioconversion of food waste into highvalue products by immobilized enzymes to meet bio-economy challenges and opportunities - A review. Food Research International, 123, 226-240.

Cohen, R., Persky, L., \& Hadar, Y. (2002). Biotechnological applications and potential of wood-degrading mushrooms of the genus Pleurotus. Applied Microbiology and Biotechnology, 58(5), 582-594.

Dai, J., \& Mumper, R. J. (2010). Plant phenolics: Extraction, analysis and their antioxidant and anticancer properties. Molecules, 15(10), 7313-7352.

Ding, C., Liu, Q., Li, P., Pei, Y., Tao, T., Wang, Y., ... Shao, X. (2019). Distribution and quantitative analysis of phenolic compounds in fractions of Japonica and Indica rice. Food Chemistry, 274, 384-391.

Dykes, L., \& Rooney, L. W. (2007). Phenolic compounds in cereal grains and their health benefits. Cereal Foods World, 52(3), 105-111.

Espinosa-Páez, E., Alanis-Guzmán, M., Hernández-Luna, C., Báez-González, J., AmayaGuerra, C., \& Andrés-Grau, A. (2017). Increasing antioxidant activity and protein digestibility in Phaseolus vulgaris and Avena sativa by fermentation with the Pleurotus ostreatus fungus. Molecules, 22(12), 2275.

Ghorai, S., Banik, S. P., Verma, D., Chowdhury, S., Mukherjee, S., \& Khowala, S. (2009) Fungal biotechnology in food and feed processing. Food Research International, 42(5-6), 577-587.

Karim, M., Daryaei, M. G., Torkaman, J., Oladi, R., Ghanbary, M. A. T., \& Bari, E. (2016) In vivo investigation of chemical alteration in oak wood decayed by Pleurotus ostreatus. International Biodeterioration \& Biodegradation, 108, 127-132.

Lockowandt, L., Pinela, J., Roriz, C. L., Pereira, C., Abreu, R. M. V., Calhelha, R. C., .. Ferreira, I. C. F. R. (2019). Chemical features and bioactivities of cornflower (Centaurea cyanus L.) capitula: The blue flowers and the unexplored non-edible part. Industrial Crops and Products, 128, 496-503.

López-Alarcón, C., \& Denicola, A. (2013). Evaluating the antioxidant capacity of natural products: A review on chemical and cellular-based assays. Analytica Chimica Acta, $763,1-10$

Martínez, A. T., Camarero, S., Gutiérrez, A., Bocchini, P., \& Galletti, G. C. (2001). Studies on wheat lignin degradation by Pleurotus species using analytical pyrolysis. Journal of Analytical and Applied Pyrolysis 58-59, 401-411.

Martins, S., Mussatto, S. I., Martínez-Avila, G., Montañez-Saenz, J., Aguilar, C. N., \& Teixeira, J. A. (2011). Bioactive phenolic compounds: Production and extraction by solid-state fermentation. A review. Biotechnology Advances, 29(3), 365-373.

McDonough, C. M., Rooney, L. W., \& Serna-Saldivar, S. O. (2000). The millets. In K. Kulp (Ed.). Handbook of Cereal Science and Technology (pp. 177-201). (2nd ed.). CRC Press.

Omarini, A. B., Dambolena, J. S., Lucini, E., Jaramillo Mejía, S., Albertó, E., \& Zygadlo, J. A. (2016). Biotransformation of 1,8-cineole by solid-state fermentation of Eucalyptus waste from the essential oil industry using Pleurotus ostreatus and Favolus tenuiculus. Folia Microbiologica, 61(2), 149-157.

Omarini, A. B., Labuckas, D., Zunino, M. P., Pizzolitto, R., Fernández-Lahore, M., Barrionuevo, D., \& Zygadlo, J. A. (2019). Upgrading the nutritional value of rice bran by solid-state fermentation with Pleurotus sapidus. Fermentation, 5(2), 44.

Omarini, A. B., Plagemann, I., Schimanski, S., Krings, U., \& Berger, R. G. (2014). Crosses between monokaryons of Pleurotus sapidus or Pleurotus florida show an improved 
biotransformation of (+)-valencene to (+)-nootkatone. Bioresource Technology, 171, 113-119.

Pereira, C., Calhelha, R. C., Barros, L., \& Ferreira, I. C. F. R. (2013). Antioxidant properties, anti-hepatocellular carcinoma activity and hepatotoxicity of artichoke, milk thistle and borututu. Industrial Crops and Products, 49, 61-65.

Perez-Vizcaino, F., \& Fraga, C. G. (2018). Research trends in flavonoids and health. Archives of Biochemistry and Biophysics, 646, 107-112.

Postemsky, P. D., Bidegain, M. A., Lluberas, G., Lopretti, M. I., Bonifacino, S., Inés Landache, M., ... Omarini, A. B. (2019). Biorefining via solid-state fermentation of rice and sunflower by-products employing novel monosporic strains from Pleurotus sapidus. Bioresource Technology, 289, 121692.

Prieto, M. A., \& Vázquez, J. A. (2014). A time-dose model to quantify the antioxidant responses of the oxidative hemolysis inhibition assay (OxHLIA) and its extension to evaluate other hemolytic effectors. BioMed Research International, 2014, 15.

Randhir, R., \& Shetty, K. (2007). Mung beans processed by solid-state bioconversion improves phenolic content and functionality relevant for diabetes and ulcer management. Innovative Food Science and Emerging Technologies, 8(2), 197-204.

Sadh, P., Kumar, S., Chawla, P., \& Duhan, J. (2018). Fermentation: A boon for production of bioactive compounds by processing of food industries wastes (by-products). Molecules, 23(10), 2560.

Sánchez, C. (2009). Lignocellulosic residues: Biodegradation and bioconversion by fungi. Biotechnology Advances, 27(2), 185-194.

Sharma, R. K., \& Arora, D. S. (2014). Bioprocessing of wheat and paddy straw for their nutritional up-gradation. Bioprocess and Biosystems Engineering, 37(7), 1437-1445.

Shrivastava, B., Thakur, S., Khasa, Y. P., Gupte, A., Puniya, A. K., \& Kuhad, R. C. (2011). White-rot fungal conversion of wheat straw to energy rich cattle feed. Biodegradation, 22(4), 823-831.

Singh, H. B., Singh, B. N., Singh, S. P., \& Nautiyal, C. S. (2010). Solid-state cultivation of Trichoderma harzianum NBRI-1055 for modulating natural antioxidants in soybean seed matrix. Bioresource Technology, 101(16), 6444-6453.

Singhania, R. R., Sukumaran, R. K., Patel, A. K., Larroche, C., \& Pandey, A. (2010). Advancement and comparative profiles in the production technologies using solidstate and submerged fermentation for microbial cellulases. Enzyme and Microbial Technology, 46(7), 541-549.

Sobral, F., Sampaio, A., Falcão, S., Queiroz, M. J. R. P., Calhelha, R. C., Vilas-Boas, M., \& Ferreira, I. C. F. R. (2016). Chemical characterization, antioxidant, anti-inflammatory and cytotoxic properties of bee venom collected in Northeast Portugal. Food and Chemical Toxicology, 94, 172-177.

Soković, M., Glamočlija, J., Marin, P. D., Brkić, D., \& van Griensven, L. J. L. D. (2010). Antibacterial effects of the essential oils of commonly consumed medicinal herbs using an in vitro model. Molecules, 15(11), 7532-7546.

Soković, M., \& van Griensven, L. J. L. D. (2006). Antimicrobial activity of essential oils and their components against the three major pathogens of the cultivated button mushroom, Agaricus bisporus. European Journal of Plant Pathology, 116(3), 211-224.
Takebayashi, J., Iwahashi, N., Ishimi, Y., \& Tai, A. (2012). Development of a simple 96well plate method for evaluation of antioxidant activity based on the oxidative haemolysis inhibition assay (OxHLIA). Food Chemistry, 134(1), 606-610.

Torres-León, C., Ramírez-Guzmán, N., Ascacio-Valdés, J., Serna-Cock, L., dos Santos Correia, M. T., Contreras-Esquivel, J. C., \& Aguilar, C. N. (2019). Solid-state fermentation with Aspergillus niger to enhance the phenolic contents and antioxidative activity of Mexican mango seed: A promising source of natural antioxidants. LWT, $112,108236$.

Torres-León, C., Ramírez-Guzman, N., Londoño-Hernandez, L., Martinez-Medina, G. A., Díaz-Herrera, R., Navarro-Macias, V., ... Aguilar, C. N. (2018). Food waste and byproducts: An opportunity to minimize malnutrition and hunger in developing countries. Frontiers in Sustainable Food Systems, 2, 52.

Vaz, J. A., Heleno, S. A., Martins, A., Almeida, G. M., Vasconcelos, M. H., \& Ferreira, I. C. F. R. (2010). Wild mushrooms Clitocybe alexandri and Lepista inversa: In vitro antioxidant activity and growth inhibition of human tumour cell lines. Food and Chemical Toxicology, 48(10), 2881-2884.

Wang, Q., Cheng, J., Wang, L., Yan, S., Wang, R., Zhang, H., ... Yang, X. (2018). Valorization of spent shiitake substrate for recovery of antitumor fungal sterols by ultrasound-assisted extraction. Journal of Food Biochemistry, 42(5), e12602.

Wang, T., He, F., \& Chen, G. (2014). Improving bioaccessibility and bioavailability of phenolic compounds in cereal grains through processing technologies: A concise review. Journal of Functional Foods, 7, 101-111.

Weber, F., \& Passon, M. (2019). Chapter 7 - characterization and quantification of polyphenols in fruits. In Ronald Ross Watson (Ed.). Polyphenols in Plants (pp. 111121). (2nd ed.). Academic Press.

Yin, Z., Wu, W., Sun, C., Lei, Z., Chen, H., Liu, H., ... Wu, H. (2018). Comparison of releasing bound phenolic acids from wheat bran by fermentation of three Aspergillus species. International Journal of Food Science \& Technology, 53(5), 1120-1130.

Zhang, X.-Y., Chen, J., Li, X.-L., Yi, K., Ye, Y., Liu, G., ... Wang, Z.-G. (2017). Dynamic changes in antioxidant activity and biochemical composition of tartary buckwheat leaves during Aspergillus niger fermentation. Journal of Functional Foods, 32, 375-381.

Zhang, Z., Lei, Z., Lu, Y., Lu, Z., \& Chen, Y. (2008). Chemical composition and bioactivity changes in stale rice after fermentation with Cordyceps sinensis. Journal of Bioscience and Bioengineering, 106(2), 188-193.

Zhong, Y. (2015). Measurement of antioxidant activity. Journal of Functional Foods, 18, $757-781$.

Zoumpoulakis, P., Sinanoglou, V., Siapi, E., Heropoulos, G., \& Proestos, C. (2017) Evaluating modern techniques for the extraction and characterisation of sunflower (Hellianthus annus L.) seeds phenolics. Antioxidants, 6(3), 46.

Zygadlo, J. A., Zunino, M. P., Pizzolitto, R. P., Merlo, C., Omarini, A., \& Dambolena, J. S. (2017). Antibacterial and anti-biofilm activities of essential oils and their components. Modes of action. In M. Rai, M. Derita, \& S. Zacchino (Eds.). Essential Oils and Nanotechnology for Treatment of Microbial Diseases (pp. 326). Editorial Springer. 